\title{
High Voltage Laboratory at Queen Mary College, London
}

$\mathrm{O}^{3}$ May 6, the High Voltage Laboratory at Queen Mary College was opened by the Earl of Athlone, Chancellor of the University of London. In this university laboratory, voltages of the order of $1,000,000$ are available for the instruction of engineering students. The completion of the Laboratory has been made possible by a grant of $£ 10,000$ from the Court of the University.

The use of high voltages for the transmission of electrical energy has been a notable development in engineers since high-voltage engineering became of commercial importance, and a study of the theory of transients will be an important part of any course of instruction in high-voltage technology. While the need for a university course in the principles of highvoltage engineering has long been recognised, it has been difficult for adequate instruction to be given in the subject, because of the high cost of the necessary laboratory equipment and of the buildings.

The authorities at Queen Mary College were

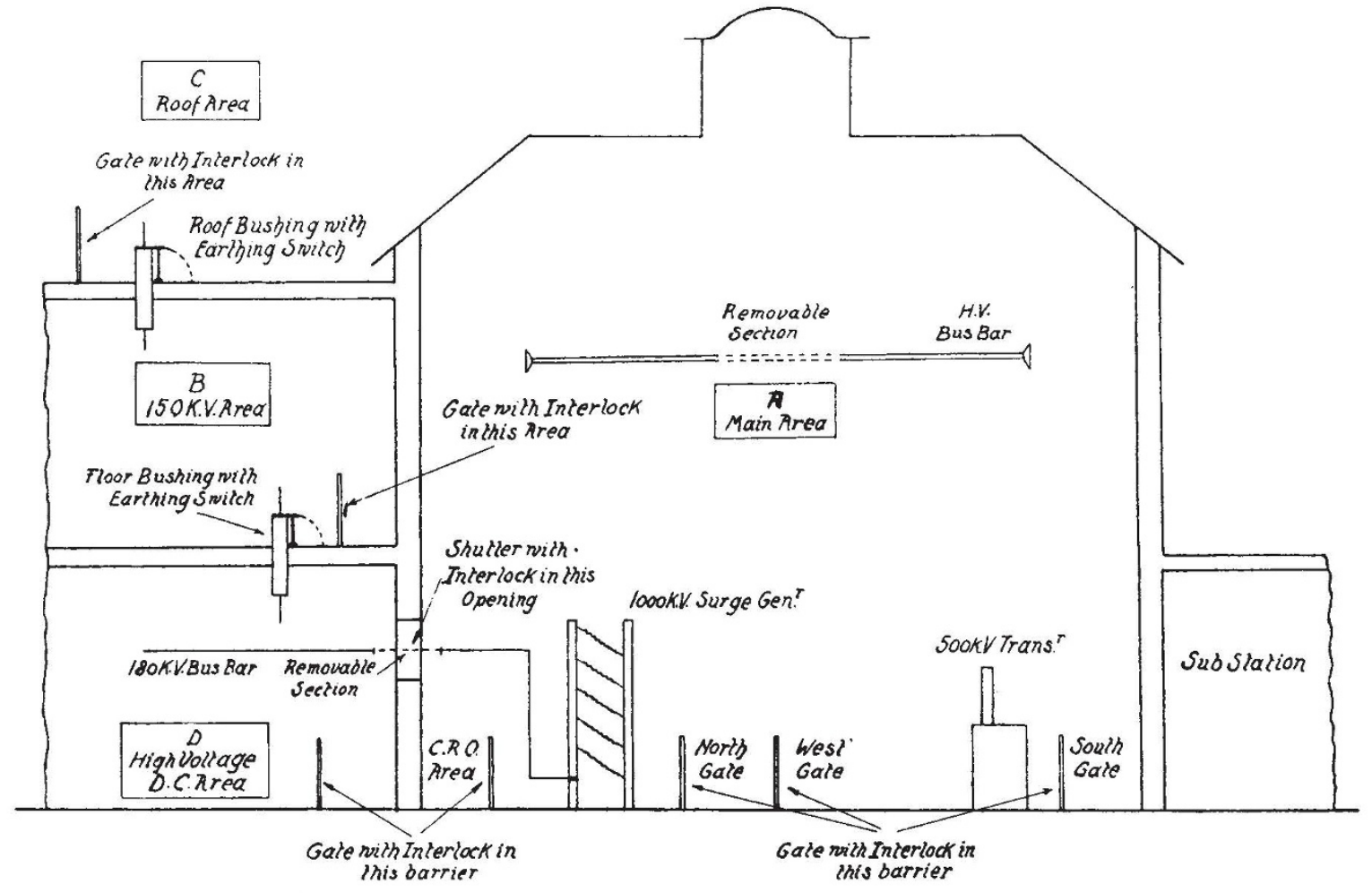

FIG. 1. Arrangement of High Voltage Laboratory, Queen Mary College, London.

electrical engineering practice in recent years. Working voltages in use to-day include $132 \mathrm{kv}$., $250 \mathrm{kv}$. and $330 \mathrm{kv}$. Still higher voltages are projected. Apparatus which has to work at these voltages must be tested by the application of even higher voltages, and the larger companies engaged in the manufacture of electrical apparatus have high-voltage testing laboratories capable of generating $1,000 \mathrm{kv}$. and, in a few instances, $2,000 \mathrm{kv}$. In consequence of this development, it is desirable that engineering graduates should possess a knowledge of the principles of highvoltage technology, and it is also desirable that research work on high-voltage problems should be undertaken by post-graduate students. Apart from this commercial aspect, the subject of high-voltage technology is eminently suitable for inclusion in a university engineering course, since it provides scope for the application of physics and mathematics to engineering problems. In particular, transient phenomena have received great attention from fortunate in possessing an existing building which could be readily adapted to accommodate highvoltage equipment, and this building is now the main High Voltage Laboratory. In the rebuilding of the Electrical Engineering Department which has just been completed, two smaller high-voltage laboratories were constructed and these are known as the $150 \mathrm{kv}$. alternating current and the high-voltage direct current laboratories. Also, the flat roof of the new building provides an excellent outdoor testing area to which various high-voltage supplies can be brought.

The layout of the complete laboratory is shown in Fig. 1. The main items of equipment are as follows: Main Laboratory, Area A.

(a) A $1,000 \mathrm{kv}$. surge-generator for the production of transient voltages.

(b) A high-voltage cathode ray oscillograph which enables a record to be taken of transient voltages having a magnitude of $1,000 \mathrm{kv}$. and a duration of a few microseconds. 
(c) A $100 \mathrm{kv}$. Schering bridge for the measurement of losses in dielectrics while these are subjected to high voltages. The equipment includes a 'no loss' condenser using compressed air as dielectric.

(d) Two transformers connected in cascade to give $500 \mathrm{kv}$, at a frequency of 50 cycles per second. The primary supply to these transformers is given by a motor-alternator set of which the motor has a rating of 60 B.H.P. and the alternator a rating of $250 \mathrm{kva}$. Great care has been taken in the design of the alternator to ensure that its output voltage wave shall be practically free from harmonics under all conditions of operation.

(e) A $750 \mathrm{~mm}$. sphere-gap with the spheres arranged vertically above one another, the lower sphere being moved by a motor-operated mechanism controlled from the main control desk. The sphere gap is used for measuring high voltages, both 50 cycle and impulse. It is arranged for use as a crest-voltmeter when required, the spheres then forming the high-voltage condenser of the crest-voltmeter.

$150 \mathrm{kv}$. Alternating Current Laboratory, Area B. This area contains a $150 \mathrm{kv}$. single phase transformer and will be used to give preliminary instruction to students in high-voltage work. It will also be used for research work.

Roof, Area $C$. This area is on the roof of the new building, and supplies can be brought to it from areas $B$ and $D$. The area will be used for making tests on outdoor-type insulators under various atmospheric conditions.

Direct Current Laboratory, Area $D$. Here is a $180 \mathrm{kv}$. direct current generator consisting of condensers and thermionic rectifying valves arranged as a 2 -stage voltage multiplying circuit. This generator is used as the supply source for the surgegenerator, but it will also be used for other purposes.

The laboratory layout has been carefully arranged so that the more expensive items of the equipment can be used in as many different areas as possible. High voltages are, of course, extremely dangerous and the greatest care has been taken to eliminate risk so far as possible. All the high-voltage testing areas are surrounded by expanded metal barriers. Entrance to the areas is obtained through doors in the barriers, and these are fitted with gate-switches which automatically switch off any high voltage in the area as soon as the door is opened.

The Laboratory is one of the best equipped of its kind in the world. It is hoped that it will serve to supply the electrical industry with engineers having an adequate knowledge of the fundamental principles of high-voltage engineering, and competent to handle the distinctive apparatus used in that branch of engineering. It is also hoped that existing knowledge of high-voltage phenomena will be extended as a result of research work done in the Laboratory.

W. J. JoHN.

\section{Zoogeographical Divisions}

A LTHOUGH the Palæarctic zoogeographical region, comprising the whole continent of Europe, a great part of Asia and northern Africa, is undoubtedly the best explored as regards its fauna, there has been no satisfactory modern scheme of its sub-divisions. This gap has now been filled* by the veteran Russian entomologist, A. P. Semenov-TianShanskij, son of the famous explorer of Tian-Shan.

The work represents the results of fifty years' study of the distribution of recent Palæarctic Coleoptera, while the geological history of the countries involved and their fossil fauna are also taken into account. Brief characteristics are given of the four sub-regions recognised by the author, and of the provinces into which each sub-region is divided. These sub-regions are as follows :

(1) Europoeo-Siberian sub-region, characterised by a fauna relatively poor in the number of genera represented, with a low percentage of endemic genera. This fauna is a greatly impoverished Tertiary one. Five provinces are recognised, namely, Arctic, Taiga, Forest, Steppe and the Caucasus province.

(2) Mediterranean sub-region, with seven provinces (Canarian, western Mediterranean, Saharan, eastern Mediterranean, Sumerian, Syrian, Hyrcanian). This is populated by a fauna regarded as an immediate development of the Pliocene fauna which has escaped here the influence of the Glacial periods. In some of the provinces, such as the Canarian and the Hyrcanian, some Miocene and even Oligocene relics still exist.

* "Les limites et les subdivisions zoogéographiques de la Région poléarctique pour les animaux terrestres basées sur la distribution géographique des insectes Coleoptères". By André Semenov-Tian1936.)

\section{of the Palæarctic Region}

(3) Central-Asian sub-region. This is an innovation which is supported by strong evidence. Its fauna has some relation to that of the Mediterranean subregion, differing from it in two respects. On one hand, many Mediterranean genera and even families have died out here, as a result of desiccation of the country. On the other hand, the desiccation resulted in a great development of numerous progressive endemics characterised by remarkable adaptations to desert life, both in structure and in habits. These evolutionary processes are still very active in several centres of the sub-region, which includes five provinces, namely, the Iranian, Turanian, Dzhungarian, Kirghizian and Mongolian.

(4) Palcearchearctic sub-region. This is another new conception. It occupies the south-east of Asia, extending to the Himalayas. Its fauna contains a high percentage of forms which are now mainly tropical, including eight families not represented elsewhere in the Palæarctic region. There are also many Tertiary relics which have survived on the spot since the Miocene and Oligocene. The following eight provinces are recognised: Manchurian, Corean, Japanese, inner Chinese, southern Chinese, Yunnanese, Tibetan and Himalayan.

While certain of the sub-divisions may appear too novel to some zoogeographers, the scheme proposed by the author is obviously superior to all previous ones, and deserves the close attention of anyone working on distributional problems. It is most regrettable that such an important contribution to biogeography should have appeared only in Russian, without even a summary in some other language. Explanations to the map included are, however, given in Latin as well, which will make it more widely available. 